OPEN ACCESS

Edited by:

Daniela D. Pollak,

Medical University of Vienna, Austria

Reviewed by:

Eva Millesi,

University of Vienna, Austria

Heinrich S. Gompf,

University of California Davis, USA

${ }^{*}$ Correspondence:

Jo E. Lewis

jo.lewis@nottingham.ac.uk

Specialty section:

This article was submitted to

Sleep and Chronobiology,

a section of the journal

Frontiers in Neurology

Received: 11 January 2017

Accepted: 20 February 2017

Published: 10 March 2017

Citation:

Lewis JE and Ebling FJP (2017)

Tanycytes As Regulators of Seasonal Cycles in Neuroendocrine Function.

Front. Neurol. 8:79.

doi: 10.3389/fneur.2017.00079

\section{Tanycytes As Regulators of Seasonal Cycles in Neuroendocrine Function}

\author{
Jo E. Lewis* and Francis J. P. Ebling \\ School of Life Sciences, University of Nottingham Medical School, Queen's Medical Centre, Nottingham, UK
}

Annual cycles of physiology and behavior are highly prevalent in organisms inhabiting temperate and polar regions. Examples in mammals include changes in appetite and body fat composition, hibernation and torpor, growth of antlers, pelage and horns, and seasonal reproduction. The timing of these seasonal cycles reflects an interaction of changing environmental signals, such as daylength, and intrinsic rhythmic processes: circannual clocks. As neuroendocrine signals underlie these rhythmic processes, the focus of most mechanistic studies has been on neuronal systems in the hypothalamus. Recent studies also implicate the pituitary stalk (pars tuberalis) and hypothalamic tanycytes as key pathways in seasonal timing. The pars tuberalis expresses a high density of melatonin receptors, so is highly responsive to changes in the nocturnal secretion of melatonin from the pineal gland as photoperiod changes across the year. The pars tuberalis in turn regulates tanycyte function in the adjacent hypothalamus via paracrine signals. Tanycytes are radial glial cells that persist into adulthood and function as a stem cell niche. Their cell soma are embedded in the ependymal lining of the third ventricle, and they also send elaborate projections through the arcuate nucleus, many of which terminate on capillaries in the median eminence. This anatomy underlies their function as sensors of nutrients in the circulation, and as regulators of transport of hormones and metabolites into the hypothalamus. In situ hybridization studies reveal robust seasonal changes in gene expression in tanycytes, for example, those controlling transport and metabolism of thyroid hormone and retinoic acid. These hormonal signals play a key role in the initial development of the brain, and experimental manipulation of thyroid hormone availability in the adult hypothalamus can accelerate or block seasonal cyclicity in sheep and Siberian hamsters. We hypothesize that seasonal rhythms depends upon reuse of developmental mechanisms in the adult hypothalamus and that tanycytes are key orchestrators of these processes.

Keywords: tanycyte, season, photoperiod, neuroendocrinology, stem cells

\section{INTRODUCTION}

Investigation of the central mechanisms underlying seasonal cycles in energy balance has provided new insights into the fundamental control systems of appetite and energy expenditure in the brain. Homeostatic mechanisms governing the short-term control of energy balance, for example, the timing of meals and the response to acute fasting, have been extensively studied in laboratory animal models. This body of work has given us great insight into the autonomic and endocrine signals emanating from the gastrointestinal tract and white adipose tissue that communicate to integrative 
centers of the hypothalamus and brainstem (1). However, the evidence that changes in homeostatic gene expression underlie long-term season cycles in energy balance is very limited $(2,3)$. In seasonal mammals, rheostatic mechanisms that govern the long-term control of energy balance reflect a higher order set of processes controlling the neuroendocrine system (4). A key element of this rheostatic system comprises hypothalamic tanycytes (Figure 1). These are radial glial cells whose cell soma in embedded in the ependymal lining of the third ventricle (Figure 1). They possess elaborate projections that communicate with hypothalamic nuclei implicated in energy balance (5). Subtypes of tanycyte have been identified on the basis of their location and their proximity to hypothalamic nuclei: $\alpha 1$ and $\alpha 2$ tanycytes appose the dorsomedial and ventromedial nuclei, whereas $\beta 1$ and $\beta 2$ tanycytes border the arcuate nucleus and median eminence. Interestingly, $\beta 2$ tanycytes differ from the other subtypes as they have direct access to circulating plasma (6). These tanycytes in the ventral region of the third ventricle are uniquely fenestrated and selectively permeable, allowing passive and active transport of molecules from the circulating blood supply in the median eminence into the cerebroventricular fluid in the third ventricle (7). While there is conflicting evidence for homeostatic-induced
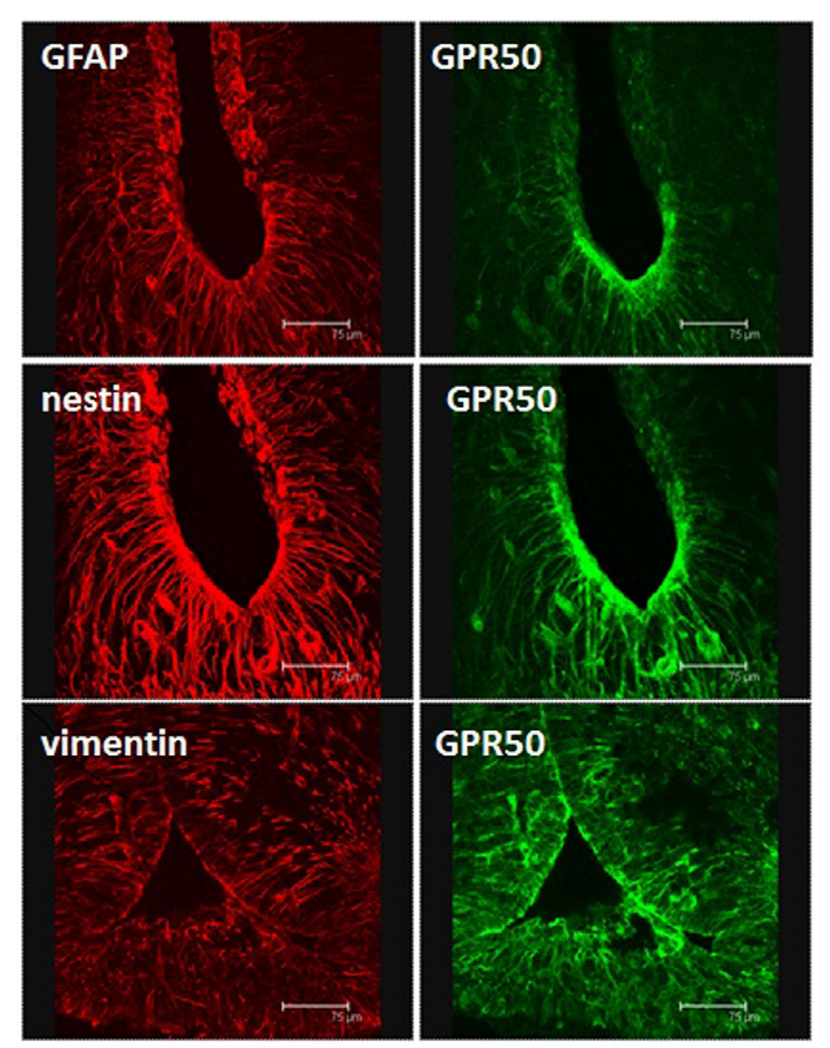

FIGURE 1 | Immunohistochemical identification of tanycytes in coronal sections through the mediobasal hypothalamus of a Siberian hamster. Polyclonal rabbit antisera detect glial fibrillary acidic protein, or the intermediate filaments nestin or vimentin. Sections are also stained with a goat polyclonal directed against the melatonin-related receptor GPR50. Scale bars $=75 \mu \mathrm{m}$. Image from Fowler and Ebling, University of Nottingham. gene expression changes in tanycytes, there is consistent evidence between studies and species for seasonal/photoperiodic-induced changes in gene expression (Figure 2). In particular, tanycytes have been identified as key determinants of long-term seasonal changes in ingestive behavior and energy metabolism through their role in transport and regulation of thyroid hormone availability in the hypothalamus (8). The aim of this review is to summarize our current understanding of tanycyte biology and outline their key roles in nutrient and hormone sensing, and in directing neuroplasticity, and thereby regulating hypothalamic control of energy metabolism.

\section{HYPOTHALAMIC TANYCYTES AS MEDIATORS OF ENERGY HOMEOSTASIS}

The blood-brain barrier (BBB) is a feature of the cerebral vasculature that restricts and regulates access of molecules to the brain, and therefore acts as a gatekeeper to the hypothalamic nuclei and beyond (9-11). However, despite the prominence of tanycytes within the ependymal layer of the third ventricle and their expression of a wide range of hormone receptors and nutrient

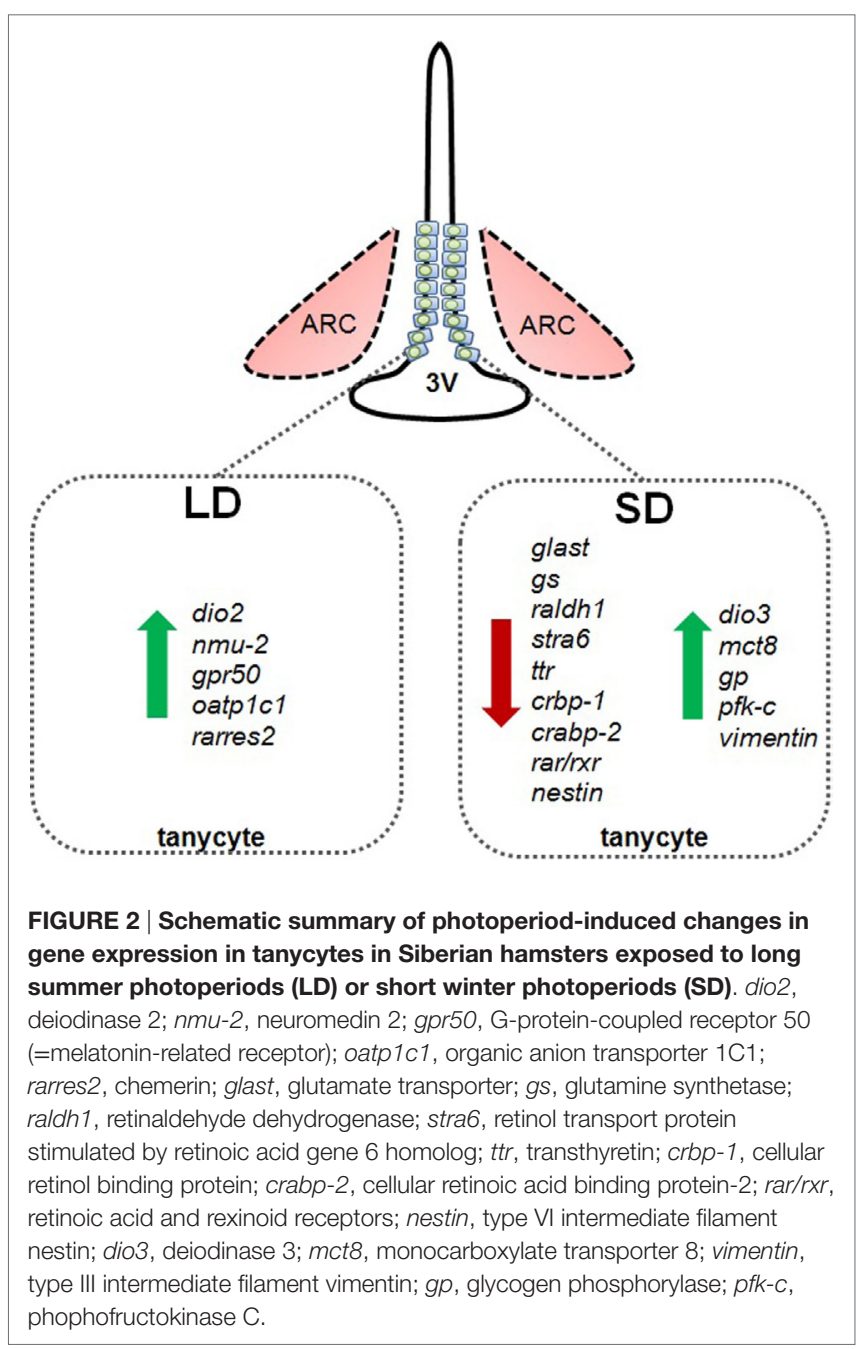


sensors, their role in energy homeostasis is hotly debated. Early studies on tanycytes focused upon their barrier function (6). In response to food deprivation and a resulting fall in blood glucose, tanycytes undergo morphological changes and increase vascular permeability via enhanced secretion of VEGF-A (10). These reversible morphological alterations at the $\mathrm{BBB}$ suggest that nutritional state modulates the access of metabolic signals via tanycytes from the periphery to hypothalamic nuclei critical for energy homeostasis. However, the role of tanycytes as mediators of energy homeostasis extends beyond the morphological to the adaptive homeostatic and neuroendocrine.

In response to a fast, the hypothalamus-pituitary-thyroid (HPT) axis is downregulated through a reduction of thyrotropinreleasing hormone (TRH) synthesis in the paraventricular nucleus (PVN). The neurons of the PVN project to the median eminence and the terminals are in close proximity to the projections of $\beta 2$ tanycytes. These cells express pyroglutamyl peptidase II (PPII), an ectopeptidase that hydrolyzes $\mathrm{TRH}$, and thus controls the amount of TRH available to cause thyroid-stimulating hormone (TSH) synthesis and secretion in the anterior pituitary. In situ hybridization studies demonstrated that PPII and deiodinase 2 (DIO2) were increased in tanycytes following a fast (12). DIO2 removes an outer ring iodine atom, so converts the inactive form of thyroid hormone (thyroxine; T4) into the biologically active form triiodothyronine (T3). This is a common theme in tanycyte biology. Interestingly, increased DIO2 activity in tanycytes suppresses TRH secretion from the PVN via the local increase in T3 availability in the hypothalamus, and subsequent studies demonstrated that DIO2 in tanycytes is essential for regulation of the HPT axis (13-15).

An intriguing feature of tanycyte biology is that these cells are also activated by signals emanating from the adjacent pars tuberalis in the pituitary stalk. For example, TSH receptors located in tanycytes are activated by TSH $\beta$ produced in the pars tuberalis. This signal is transduced via both activation of adenylate cyclase and phosphorylation of extracellular signal-regulated kinases (ERK1/2), resulting in increases in DIO2 mRNA expression (16). In addition to fasting, overnutrition results in changes in tanycyte biology; ghrelin uptake/transport is attenuated following neonatal overfeeding (by reducing litter size) in the mouse (17). The lipopolysaccharide-induced cytokine upregulation of DIO2 expression in tanycytes and the stimulatory actions of pituitary adenylate cyclase-activating polypeptide both occur via increased intracellular cAMP and the NF- $\mathrm{BB}$ pathway $(18,19)$.

Interestingly, tanycytes express the insulin-independent glucose transporters GLUT1 and GLUT2, and also glucokinase. Indeed, in hypothalamic slice cultures, tanycytes respond to exogenously administered glucose, which stimulates $\mathrm{Ca}^{2+}$ ion fluxes and ATP release; effects that are then propagated across neighboring cells (20). This is further evidence that they function as nutrient sensors $(21,22)$. Furthermore, tanycytes express a number of enzymes involved in lipid metabolism, and monocarboxylate transporters, a family of transporters that mediate the facilitated diffusion of lactate, pyruvate, and ketone bodies. This suggests further possible mechanisms, whereby tanycytes mediate neuronal responses in the hypothalamus to changes in peripheral carbohydrate and fat metabolism $(23,24)$. Recently, a metabolic link between tanycytes and astrocytes, likely to impact hypothalamic lipid sensing, has been suggested (25). In addition, in leptin receptor deficient mice $(d b / d b)$ and in mice treated with a leptin antagonist, leptin accumulates in the median eminence but fails to appear in the mediobasal hypothalamus, providing evidence that leptin's signaling cascade begins in tanycytes in the median eminence, and then transitions to hypothalamic nuclei and neurons (26).

Further evidence supporting the neuroendocrine roles of tanycytes is provided by a series of experiments that targeted the fibroblast growth factor receptor $1 \mathrm{c}$ isoform (FGFR1c). It was previously shown that antibody-mediated targeting of the FGFR1c receptor reduced body weight, adiposity, and insulin resistance in animal models of obesity and type II diabetes (27-29). Subsequent in situ hybridization studies in the Siberian hamster revealed a high level expression of the FGFR1c in tanycytes, consistent with previous qPCR studies in the mouse $(30,31)$. Targeting of the FGFR1c in the long day (LD) obese Siberian hamster peripherally and centrally via intracerebroventicular infusion of a monoclonal FGFR1c antibody reduced food intake and body weight, which was associated with a decrease in expression of DIO2 in the ependymal cell layer containing tanycytes (31). This further supports the hypothesis that tanycytes are an important component of the mechanism by which the hypothalamus integrates central and peripheral signals to regulate energy homeostasis. It also highlights a potential role in seasonal metabolic cycles, as the response to tanycyte manipulation was attenuated in short-day (SD) lean animals.

\section{HYPOTHALAMIC TANYCYTES AS MEDIATORS OF SEASONAL CYCLES}

In response to seasonal changes in daylength, mammals such as the Siberian hamster and the F344 strain of photoperiodic rat undergo substantive behavioral and physiological adaptations, for example, in body composition, growth, and reproductive activity $(32,33)$. The retina is crucial to such adaptations; for example, optic nerve transection or bilateral enucleation prevents the synchronicity of seasonal reproduction $(34,35)$. Photoneuroendocrine pathways, where retinal information is conveyed to the suprachiasmatic nucleus, are well characterized, as is the neurochemical index provided by the secretion of melatonin by the pineal gland in response to changes in daylength (36). More recently, we have begun to appreciate the role and importance of the pars tuberalis, part of the pituitary stalk that contains a high density of melatonin receptors in all seasonal mammals and communicates to adjacent tanycytes in the hypothalamus (37). Emerging evidence suggests that tanycytes are an integral part of the mechanism that facilitates seasonal physiology and behavior in seasonal mammals. In addition to melatonin-regulated changes in secretion of paracrine factors including $\mathrm{TSH} \beta$ and neuromedin $\mathrm{U}$ (NMU), this region undergoes structural changes in response to changing photoperiod, particularly in the thyrotrophs, which produce TSH (38-40). One consequence of this is that a significantly lower percentage of cells display exocytotic activity in SD, supporting the hypothesis that the pars tuberalis functions as an interface 
between photoperiodic stimuli and the endocrine system (41). Furthermore, the regulation of thyrotrophs is a melatonindependent process; pinealectomy blocks the SD-induced downregulation of TSH $\beta$ production, and treatment with melatonin can mimic the actions of SD $(42,43)$. As noted above, the TSH $\beta$ subunit has been shown to signal to tanycytes, and studies on the Syrian hamster, photoperiodic rat, and sheep have revealed that tanycytes express the TSH receptor, while local infusion of TSH $\beta$ into the third ventricle upregulates DIO2 in these glial cells (44, $45)$. It is of note that in juvenile photoperiodic rats, $\operatorname{TSH} \beta$ also downregulates deiodinase 3 (DIO3) expression in the ependymal cell layer (44).

DIO3 is an enzyme in the tanycyte cell layer that opposes the action of DIO2, as it removes an inner ring iodine, and therefore deiodinates T4 into reverse T3, which is biologically inactive. Furthermore, it deiodinates T3 into the inactive metabolite diiodothyronine (T2). In the adult Siberian hamster, rather than a LD-induced upregulation of DIO2 (Figure 2) that increases the local availability of T3, DIO3 is upregulated in response to SD (Figure 2), inactivating T3 or converting the precursor to T2 (32). This phenomenon is not limited to the Siberian hamster, it is also seen in male sheep exposed to SD for 14 weeks (46). It is predicted that the enhanced expression of DIO3 would have the same effect on local thyroid hormone availability in the hypothalamus as the downregulation of DIO2 observed in most other photoperiodic species (32). The biological significance of this predicted change in hypothalamic T3 concentrations was directly tested in the Siberian hamster by surgically inserting micro T3 implants into the hypothalamus, and exposing hamsters to changes in photoperiod. Such implants blocked the SD-induced weight loss and catabolism of fat depots and prevented SD-induced testicular regression (8). Correspondingly, T3-releasing implants stimulated appetite and induced body weight gain and reproductive recrudescence when placed in hamsters previously exposed to SD (47). The T3 microimplants blocked the SD-induced increase in VGF expression in the dorsomedial posterior arcuate nucleus, a potential regulator of seasonal changes in appetite and energy expenditure (8).

In addition to the clear effects of $\mathrm{TSH} \beta$ derived from the pars tuberalis on deiodinase gene expression in tanycytes, other paracrine mechanisms may also be important in the regulation of deiodinases and tanycyte function. For example, ICV infusion of NMU decreases food intake and in obese mouse models increases physical activity, energy expenditure, and thermogenesis. Furthermore, $\mathrm{NMU}^{-/-}$mice exhibit hyperphagia, increased body weight, and reduced energy expenditure. The actions of NMU are conferred by the NMU-2 receptor (48). Interestingly in photoperiodic rats in LD, NMU gene expression is upregulated in the pars tuberalis, while its receptor is upregulated in tanycytes $(44,49)$. It was subsequently shown that local infusion of NMU into the third ventricle of photoperiodic rats held in SD upregulated DIO2, thus mimicking the LD state (44). Similarly, the GPR50 receptor, which is homologous to the melatonin receptor MT1 but does not bind melatonin, is expressed in tanycytes (Figure 1) and has been implicated in adaptive thermogenesis and torpor (50). GPR50-null mice are resistant to diet-induced obesity; however, when fasted, they more readily enter a state of torpor. These effects appear to be mediated through TRH, as entry into torpor is reversed by treatment with TRH receptor agonists $(51,52)$. In the Siberian hamster exposed to SD, GPR50 expression is significantly reduced in tanycytes (Figure 2); this may contribute to bouts of adaptative thermogenesis, torpor, and more broadly energy balance (53). In response to SD, the thyroid hormone transporter monocarboxylate 8 (MCT8) is increased in tanycytes in the Siberian hamster, while fasting reversed this effect, further evidence supporting the role of thyroid hormone and tanycytes in the photoperiodic regulation of seasonal biology (54). Additionally, the thyroid hormone transporter organic anion transporter family member $1 \mathrm{C} 1$ (Oatp1c1) is photoperiodically regulated in tanycytes so potentially contributes to seasonal alterations in thyroid hormone transport [Figure 2; (55)]. Interestingly, the lactate (MCT2) and glutamate (GLAST) transporters, as well as glutamine synthetase, are reduced in tanycytes during SD (Figure 2), suggesting glutamate uptake and production of glutamine are diminished. Furthermore, glycogen phosphorylase and phosphofructokinase- $\mathrm{C}$, rate-limiting steps in the metabolism of glycogen to glucose, are increased in tanycytes during SD [Figure 2; (56)].

Interestingly, T3 rapidly induces the RA-synthesizing enzyme retinaldehyde dehydrogenase 1 (RALDH1) in tanycytes (57). In photoperiodic rats, RALDH1 and -2 expression is reduced in $\mathrm{SD}$, while the retinol transport protein stimulated by retinoic acid gene 6 homolog (STRA6) is reduced by $\operatorname{SD}(58,59)$. Furthermore, expression of transthyretin (TTR), a common transporter for vitamin $\mathrm{A}$ and its metabolite retinoic acid, is downregulated under SD in the tanycytes of photoperiodic rats, while cellular retinoic acid binding protein (CRBP1), a retinoic acid transport protein, is downregulated in SD photoperiods in tanycytes in Siberian hamsters. The latter effects are reversed by pinealectomy, which suggests that the mechanism is dependent upon melatonin (53). Furthermore, cellular retinoic acid binding protein-2 (CRABP-2) and members of the nuclear retinoic acid receptor and retinoid $\mathrm{X}$ receptor families are reduced in response to SD in the Siberian hamster $(53,60)$. Interestingly, retinoic acid regulates the ability of tanycytes to proliferate and generate new cells in the hypothalamus highlighting another possible role for tanycytes (5).

\section{HYPOTHALAMIC TANYCYTES AS A STEM CELL NICHE}

A number of studies support the existence of hypothalamic stem cells capable of generating new neurons in a variety of species. However, the location and identity are hotly disputed. Recent in vitro and in vivo studies have suggested that they are located within the mediobasal hypothalamus parenchyma and could represente NG2-expressing oligodendrocyte progenitor cells (61, 62 ). Contrasting studies have suggested that subpopulations of tanycytes constitute the source (63-66). This in itself, however, is controversial as both $\alpha$ - and $\beta$-tanycytes have been identified as the possible neurogenic niche, as well as a possible role for insulin-like growth factor $(63,65,67)$. Interestingly, in one study, exposure of mice to a high fat diet depleted numbers of putative 
hypothalamic stem cells, which was associated with impaired glucose tolerance and subsequent obesity (68). However, rather contradictory results were reported in the study that demonstrated increased numbers of cells labeled with the thymidine analog BrdU in the hypothalamic ventricular zone in mice maintained on a high fat diet (64). Furthermore, in the latter study, focused irradiation of the hypothalamus inhibited cell division that was associated with reduced body weight gain on a high fat diet, suggesting that new cells produced in the hypothalamus might have an anabolic function (64). More recently, increased ciliary neurotrophic factor signaling was detected in tanycytes close to the median eminence in obese mice on high fat diet, further supporting the hypothesis that positive energy balance is associated with enhanced hypothalamic neurogenesis (69).

In addition to high fat diet, photoperiodic stimuli regulates cell division in the adult hypothalamus. Exposure to SD increased vimentin labeling in hypothalamic tanycytes of sheep and increased numbers of BrdU-positive cells in the sheep hypothalamus, though a substantive proportion of these expressed a microglia marker so were not destined to become neuronal $(70,71)$. Following the transition from LD to SD, an increase in cellular proliferation is apparent in the hypothalamus of Syrian hamsters; in the Siberian hamster, the intermediate filament protein, and neural stem cell marker nestin is downregulated during SD $(53,72)$. Further studies are clearly required to determine whether the reported seasonal changes in BrdU uptake or expression of cell cycle markers such as Ki67 truly reflect altered neurogenesis, or whether new cells integrate into functional circuits in the hypothalamus. However, given the evidence above regarding photoperiod-induced changes in thyroid hormone availability in the hypothalamus, and the extensive evidence that the thyroid hormone system is implicated in neural division and differentiation, it seems very likely that plasticity of cell division and connectivity in the hypothalamus will be identified as a core feature of seasonal cycles $(73,74)$. Finally, it has been observed that the ability of tanycytes to proliferate postnatally declines with age: incorporation of the S-phase marker BrdU in $\beta$-tanycytes

\section{REFERENCES}

1. Druce M, Bloom SR. The regulation of appetite. Arch Dis Child (2006) 91(2):183-7. doi:10.1136/adc.2005.073759

2. Ebling FJ. On the value of seasonal mammals for identifying mechanisms underlying the control of food intake and body weight. Horm Behav (2014) 66(1):56-65. doi:10.1016/j.yhbeh.2014.03.009

3. Reddy AB, Cronin AS, Ford H, Ebling FJ. Seasonal regulation of food intake and body weight in the male Siberian hamster: studies of hypothalamic orexin (hypocretin), neuropeptide Y (NPY) and pro-opiomelanocortin (POMC). Eur J Neurosci (1999) 11(9):3255-64. doi:10.1046/j.1460-9568.1999. 00746.x

4. Mrosovsky N. Rheostasis: The Physiology of Change. New York: Oxford University Press (1990).

5. Bolborea M, Dale N. Hypothalamic tanycytes: potential roles in the control of feeding and energy balance. Trends Neurosci (2013) 36(2):91-100. doi:10.1016/j.tins.2012.12.008

6. Rodriguez EM, Blazquez JL, Pastor FE, Pelaez B, Pena P, Peruzzo B, et al. Hypothalamic tanycytes: a key component of brain-endocrine interaction. Int Rev Cytol (2005) 247:89-164. doi:10.1016/s0074-7696(05)47003-5

7. Mullier A, Bouret SG, Prevot V, Dehouck B. Differential distribution of tight junction proteins suggests a role for tanycytes in blood-hypothalamus barrier deteriorates between P7 and P45, while no incorporation is seen by 12 months of age (63). Furthermore, tanycyte numbers declines by almost $30 \%$ with increasing age as well as inducing significant morphological and anatomical changes; processes become thicker and disorganized in the pericapillary zone, with a loss of perpendicular orientation (75). This poses further tantalizing questions regards their metabolic role in relation to aging, and whether seasonal cycles might be considered as arrested or even reversible aging.

\section{CONCLUSION}

Identifying the mechanisms by which mammals naturally regulate appetite and body composition across the year should provide insights into how long-term improvements in metabolic health could be promoted in man. Tanycytes are the only cell type in the hypothalamus that shows major changes in gene expression across a seasonal cycle, so are a likely regulator of long-term changes in energy balance. Tanycytes have a privileged position as a nutrient and hormone sensor with projections to the metabolic brain, and potentially function as a neural stem cell niche, highlighting a number of mechanisms that could influence energy intake and expenditure in the long term. Experimental studies in the hamster have already confirmed that changes in thyroid hormone processing by tanycytes are part of this seasonal programming of the hypothalamus.

\section{AUTHOR CONTRIBUTIONS}

$\mathrm{JL}$ and FE drafted and revised the manuscript.

\section{FUNDING}

Research in the authors' laboratory is currently supported by the Biotechnology and Biological Sciences Research Council (BBSRC UK) via project grants BB/M001555/1 and BB/ M021629/1.

regulation in the adult mouse brain. J Comp Neurol (2010) 518(7):943-62. doi: $10.1002 /$ cne. 22273

8. Barrett P, Ebling FJ, Schuhler S, Wilson D, Ross AW, Warner A, et al. Hypothalamic thyroid hormone catabolism acts as a gatekeeper for the seasonal control of body weight and reproduction. Endocrinology (2007) 148(8):3608-17. doi:10.1210/en.2007-0316

9. Frayling C, Britton R, Dale N. ATP-mediated glucosensing by hypothalamic tanycytes. JPhysiol (2011) 589(Pt 9):2275-86. doi:10.1113/ jphysiol.2010.202051

10. Langlet F, Levin BE, Luquet S, Mazzone M, Messina A, Dunn-Meynell AA, et al. Tanycytic VEGF-A boosts blood-hypothalamus barrier plasticity and access of metabolic signals to the arcuate nucleus in response to fasting. Cell Metab (2013) 17(4):607-17. doi:10.1016/j.cmet.2013.03.004

11. Yeo GS, Heisler LK. Unraveling the brain regulation of appetite: lessons from genetics. Nat Neurosci (2012) 15(10):1343-9. doi:10.1038/nn.3211

12. Lazcano I, Cabral A, Uribe RM, Jaimes-Hoy L, Perello M, Joseph-Bravo P, et al. Fasting enhances pyroglutamyl peptidase II activity in tanycytes of the mediobasal hypothalamus of male adult rats. Endocrinology (2015) 156(7):2713-23. doi:10.1210/en.2014-1885

13. Boelen A, Wiersinga WM, Fliers E. Fasting-induced changes in the hypothalamus-pituitary-thyroid axis. Thyroid (2008) 18(2):123-9. doi:10.1089/thy.2007.0253 
14. Fonseca TL, Correa-Medina M, Campos MP, Wittmann G, Werneck-deCastro JP, Arrojo e Drigo R, et al. Coordination of hypothalamic and pituitary T3 production regulates TSH expression. J Clin Invest (2013) 123(4):1492-500. doi:10.1172/jci61231

15. Sanchez E, Singru PS, Fekete C, Lechan RM. Induction of type 2 iodothyronine deiodinase in the mediobasal hypothalamus by bacterial lipopolysaccharide: role of corticosterone. Endocrinology (2008) 149(5):2484-93. doi:10.1210/ en.2007-1697

16. Bolborea M, Helfer G, Ebling FJ, Barrett P. Dual signal transduction pathways activated by TSH receptors in rat primary tanycyte cultures. J Mol Endocrinol (2015) 54(3):241-50. doi:10.1530/jme-14-0298

17. Collden G, Balland E, Parkash J, Caron E, Langlet F, Prevot V, et al. Neonatal overnutrition causes early alterations in the central response to peripheral ghrelin. Mol Metab (2015) 4(1):15-24. doi:10.1016/j.molmet.2014.10.003

18. de Vries EM, Nagel S, Haenold R, Sundaram SM, Pfrieger FW, Fliers E, et al. The role of hypothalamic NF-kappaB signaling in the response of the HPT-axis to acute inflammation in female mice. Endocrinology (2016) 157(7):2947-56. doi:10.1210/en.2016-1027

19. Egri P, Fekete C, Denes A, Reglodi D, Hashimoto H, Fulop BD, et al. Pituitary adenylate cyclase-activating polypeptide (PACAP) regulates the hypothalamo-pituitary-thyroid (HPT) axis via type 2 deiodinase in male mice. Endocrinology (2016) 157(6):2356-66. doi:10.1210/en.2016-1043

20. Dale N. Purinergic signaling in hypothalamic tanycytes: potential roles in chemosensing. Semin Cell Dev Biol (2011) 22(2):237-44. doi:10.1016/ j.semcdb.2011.02.024

21. Garcia M, Millan C, Balmaceda-Aguilera C, Castro T, Pastor P, Montecinos $\mathrm{H}$, et al. Hypothalamic ependymal-glial cells express the glucose transporter GLUT2, a protein involved in glucose sensing. J Neurochem (2003) 86(3):70924. doi:10.1046/j.1471-4159.2003.01892.x

22. Peruzzo B, Pastor FE, Blazquez JL, Schobitz K, Pelaez B, Amat P, et al. A second look at the barriers of the medial basal hypothalamus. Exp Brain Res (2000) 132(1):10-26. doi:10.1007/s002219900289

23. Akmayev IG, Popov AP. Morphological aspects of the hypothalamic-hypophyseal system. VII. The tanycytes: their relation to the hypophyseal adrenocorticotrophic function. An ultrastructural study. Cell Tissue Res (1977) 180(2):263-82.

24. Elizondo-Vega R, Cortes-Campos C, Barahona MJ, Carril C, Ordenes P, Salgado M, et al. Inhibition of hypothalamic MCT1 expression increases food intake and alters orexigenic and anorexigenic neuropeptide expression. Sci Rep (2016) 6:33606. doi:10.1038/srep33606

25. Hofmann K, Lamberz C, Piotrowitz K, Offermann N, But D, Scheller A, et al. Tanycytes and a differential fatty acid metabolism in the hypothalamus. Glia (2017) 65(2):231-49. doi:10.1002/glia.23088

26. Balland E, Dam J, Langlet F, Caron E, Steculorum S, Messina A, et al. Hypothalamic tanycytes are an ERK-gated conduit for leptin into the brain. Cell Metab (2014) 19(2):293-301. doi:10.1016/j.cmet.2013.12.015

27. Foltz IN, Hu S, King C, Wu X, Yang C, Wang W, et al. Treating diabetes and obesity with an FGF21-mimetic antibody activating the betaKlotho/FGFR1c receptor complex. Sci Transl Med (2012) 4(162):162ra153. doi:10.1126/ scitranslmed.3004690

28. Sun HD, Malabunga M, Tonra JR, DiRenzo R, Carrick FE, Zheng H, et al. Monoclonal antibody antagonists of hypothalamic FGFR1 cause potent but reversible hypophagia and weight loss in rodents and monkeys. Am J Physiol Endocrinol Metab (2007) 292(3):E964-76. doi:10.1152/ajpendo.00089.2006

29. Wu AL, Kolumam G, Stawicki S, Chen Y, Li J, Zavala-Solorio J, et al. Amelioration of type 2 diabetes by antibody-mediated activation of fibroblast growth factor receptor 1. Sci Transl Med (2011) 3(113):113ra126. doi:10.1126/ scitranslmed.3002669

30. Fon Tacer K, Bookout AL, Ding X, Kurosu H, John GB, Wang L, et al. Research resource: comprehensive expression atlas of the fibroblast growth factor system in adult mouse. Mol Endocrinol (2010) 24(10):2050-64. doi:10.1210/ me.2010-0142

31. Samms RJ, Lewis JE, Lory A, Fowler MJ, Cooper S, Warner A, et al. Antibodymediated inhibition of the FGFR1c isoform induces a catabolic lean state in Siberian hamsters. Curr Biol (2015) 25(22):2997-3003. doi:10.1016/ j.cub.2015.10.010

32. Ebling FJ. Hypothalamic control of seasonal changes in food intake and body weight. Front Neuroendocrinol (2015) 37:97-107. doi:10.1016/ j.yfrne.2014.10.003
33. Tavolaro FM, Thomson LM, Ross AW, Morgan PJ, Helfer G. Photoperiodic effects on seasonal physiology, reproductive status and hypothalamic gene expression in young male F344 rats. J Neuroendocrinol (2015) 27(2):79-87. doi:10.1111/jne.12241

34. Herbert J, Stacey PM, Thorpe DH. Recurrent breeding seasons in pinealectomized or optic-nerve-sectioned ferrets. J Endocrinol (1978) 78(3):389-97. doi:10.1677/joe. 0.0780389

35. Legan SJ, Karsch FJ. Importance of retinal photoreceptors to the photoperiodic control of seasonal breeding in the ewe. Biol Reprod (1983) 29(2):316-25. doi:10.1095/biolreprod29.2.316

36. Moore RY. Neural control of the pineal gland. Behav Brain Res (1996) 73(1-2):125-30. doi:10.1016/0166-4328(96)00083-6

37. Wagner GC, Johnston JD, Tournier BB, Ebling FJ, Hazlerigg DG. Melatonin induces gene-specific effects on rhythmic mRNA expression in the pars tuberalis of the Siberian hamster (Phodopus sungorus). Eur J Neurosci (2007) 25(2):485-90. doi:10.1111/j.1460-9568.2006.05291.x

38. Hanon EA, Lincoln GA, Fustin JM, Dardente H, Masson-Pevet M, Morgan PJ, et al. Ancestral TSH mechanism signals summer in a photoperiodic mammal. Curr Biol (2008) 18(15):1147-52. doi:10.1016/j.cub.2008.06.076

39. Helfer G, Ross AW, Thomson LM, Mayer CD, Stoney PN, McCaffery PJ, et al. A neuroendocrine role for chemerin in hypothalamic remodelling and photoperiodic control of energy balance. Sci Rep (2016) 6:26830. doi:10.1038/ srep26830

40. Wittkowski W, Hewing M, Hoffmann K, Bergmann M, Fechner J. Influence of photoperiod on the ultrastructure of the hypophysial pars tuberalis of the Djungarian hamster, Phodopus sungorus. Cell Tissue Res (1984) 238(1): 213-6.

41. Merks T, Schulze-Bonhage A, Wittkowski W. Photoperiod-dependent changes in exocytotic activity in the hypophyseal pars tuberalis of the Djungarian hamster, Phodopus sungorus. Cell Tissue Res (1993) 273(2):287-91. doi:10.1007/ BF00312830

42. Bockers TM, Niklowitz P, Bockmann J, Fauteck JD, Wittkowski W, Kreutz MR. Daily melatonin injections induce cytological changes in pars tuberalis-specific cells similar to short photoperiod. J Neuroendocrinol (1995) 7(8):607-13. doi:10.1111/j.1365-2826.1995.tb00798.x

43. Bockmann J, Bockers TM, Vennemann B, Niklowitz P, Muller J, Wittkowski $\mathrm{W}$, et al. Short photoperiod-dependent down-regulation of thyrotropin-alpha and -beta in hamster pars tuberalis-specific cells is prevented by pinealectomy. Endocrinology (1996) 137(5):1804-13. doi:10.1210/endo.137.5. 8612518

44. Helfer G, Ross AW, Morgan PJ. Neuromedin U partly mimics thyroid-stimulating hormone and triggers Wnt/beta-catenin signalling in the photoperiodic response of F344 rats. J Neuroendocrinol (2013) 25(12):1264-72. doi:10.1111/ jne.12116

45. Klosen P, Sebert ME, Rasri K, Laran-Chich MP, Simonneaux V. TSH restores a summer phenotype in photoinhibited mammals via the RF-amides RFRP3 and kisspeptin. FASEB J (2013) 27(7):2677-86. doi:10.1096/fj.13-229559

46. Saenz de Miera C, Hanon EA, Dardente H, Birnie M, Simonneaux V, Lincoln GA, et al. Circannual variation in thyroid hormone deiodinases in a short-day breeder. J Neuroendocrinol (2013) 25(4):412-21. doi:10.1111/jne. 12013

47. Murphy M, Jethwa PH, Warner A, Barrett P, Nilaweera KN, Brameld JM, et al. Effects of manipulating hypothalamic triiodothyronine concentrations on seasonal body weight and torpor cycles in Siberian hamsters. Endocrinology (2012) 153(1):101-12. doi:10.1210/en.2011-1249

48. Budhiraja S, Chugh A. Neuromedin U: physiology, pharmacology and therapeutic potential. Fundam Clin Pharmacol (2009) 23(2):149-57. doi:10.1111/j.1472-8206.2009.00667.x

49. Graham ES, Turnbull Y, Fotheringham P, Nilaweera K, Mercer JG, Morgan $\mathrm{PJ}$, et al. Neuromedin $\mathrm{U}$ and neuromedin $\mathrm{U}$ receptor-2 expression in the mouse and rat hypothalamus: effects of nutritional status. J Neurochem (2003) 87(5):1165-73. doi:10.1046/j.1471-4159.2003.02079.x

50. Sidibe A, Mullier A, Chen P, Baroncini M, Boutin JA, Delagrange P, et al. Expression of the orphan GPR50 protein in rodent and human dorsomedial hypothalamus, tanycytes and median eminence. JPineal Res (2010) 48(3):263-9. doi:10.1111/j.1600-079X.2010.00750.x

51. Bechtold DA, Sidibe A, Saer BR, Li J, Hand LE, Ivanova EA, et al. A role for the melatonin-related receptor GPR50 in leptin signaling, adaptive thermogenesis, and torpor. Curr Biol (2012) 22(1):70-7. doi:10.1016/j.cub.2011.11.043 
52. Ivanova EA, Bechtold DA, Dupre SM, Brennand J, Barrett P, Luckman SM, et al. Altered metabolism in the melatonin-related receptor (GPR50) knockout mouse. Am J Physiol Endocrinol Metab (2008) 294(1):E176-82. doi:10.1152/ ajpendo.00199.2007

53. Barrett P, Ivanova E, Graham ES, Ross AW, Wilson D, Ple H, et al. Photoperiodic regulation of cellular retinol binding protein, CRBP1 [corrected] and nestin in tanycytes of the third ventricle ependymal layer of the Siberian hamster. J Endocrinol (2006) 191(3):687-98. doi:10.1677/joe.1. 06929

54. Herwig A, Wilson D, Logie TJ, Boelen A, Morgan PJ, Mercer JG, et al. Photoperiod and acute energy deficits interact on components of the thyroid hormone system in hypothalamic tanycytes of the Siberian hamster. Am J Physiol Regul Integr Comp Physiol (2009) 296(5):R1307-15. doi:10.1152/ ajpregu.90755.2008

55. Ross AW, Helfer G, Russell L, Darras VM, Morgan PJ. Thyroid hormone signalling genes are regulated by photoperiod in the hypothalamus of F344 rats. PLoS One (2011) 6(6):e21351. doi:10.1371/journal.pone.0021351

56. Nilaweera K, Herwig A, Bolborea M, Campbell G, Mayer CD, Morgan PJ, et al. Photoperiodic regulation of glycogen metabolism, glycolysis, and glutamine synthesis in tanycytes of the Siberian hamster suggests novel roles of tanycytes in hypothalamic function. Glia (2011) 59(11):1695-705. doi:10.1002/ glia. 21216

57. Stoney PN, Helfer G, Rodrigues D, Morgan PJ, McCaffery P. Thyroid hormone activation of retinoic acid synthesis in hypothalamic tanycytes. Glia (2016) 64(3):425-39. doi:10.1002/glia.22938

58. Helfer G, Ross AW, Russell L, Thomson LM, Shearer KD, Goodman TH, et al. Photoperiod regulates vitamin A and Wnt/beta-catenin signaling in F344 rats. Endocrinology (2012) 153(2):815-24. doi:10.1210/en.2011-1792

59. Shearer KD, Goodman TH, Ross AW, Reilly L, Morgan PJ, McCaffery PJ. Photoperiodic regulation of retinoic acid signaling in the hypothalamus. J Neurochem (2010) 112(1):246-57. doi:10.1111/j.1471-4159.2009. 06455.x

60. Ross AW, Webster CA, Mercer JG, Moar KM, Ebling FJ, Schuhler S, et al. Photoperiodic regulation of hypothalamic retinoid signaling: association of retinoid X receptor gamma with body weight. Endocrinology (2004) 145(1):13-20. doi:10.1210/en.2003-0838

61. Lee Y, Morrison BM, Li Y, Lengacher S, Farah MH, Hoffman PN, et al. Oligodendroglia metabolically support axons and contribute to neurodegeneration. Nature (2012) 487(7408):443-8. doi:10.1038/nature11314

62. Robins SC, Trudel E, Rotondi O, Liu X, Djogo T, Kryzskaya D, et al. Evidence for NG2-glia derived, adult-born functional neurons in the hypothalamus. PLoS One (2013) 8(10):e78236. doi:10.1371/journal.pone. 0078236

63. Haan N, Goodman T, Najdi-Samiei A, Stratford CM, Rice R, El Agha E, et al. Fgf10-expressing tanycytes add new neurons to the appetite/energy-balance regulating centers of the postnatal and adult hypothalamus. J Neurosci (2013) 33(14):6170-80. doi:10.1523/jneurosci.2437-12.2013

64. Lee DA, Bedont JL, Pak T, Wang H, Song J, Miranda-Angulo A, et al. Tanycytes of the hypothalamic median eminence form a diet-responsive neurogenic niche. Nat Neurosci (2012) 15(5):700-2. doi:10.1038/nn.3079
65. Robins SC, Stewart I, McNay DE, Taylor V, Giachino C, Goetz M, et al. alpha-Tanycytes of the adult hypothalamic third ventricle include distinct populations of FGF-responsive neural progenitors. Nat Commun (2013) 4:2049. doi:10.1038/ncomms3049

66. Xu Y, Tamamaki N, Noda T, Kimura K, Itokazu Y, Matsumoto N, et al. Neurogenesis in the ependymal layer of the adult rat 3rd ventricle. Exp Neurol (2005) 192(2):251-64. doi:10.1016/j.expneurol.2004.12.021

67. Chaker Z, George C, Petrovska M, Caron JB, Lacube P, Caille I, et al. Hypothalamic neurogenesis persists in the aging brain and is controlled by energy-sensing IGF-I pathway. Neurobiol Aging (2016) 41:64-72. doi:10.1016/ j.neurobiolaging.2016.02.008

68. McNay DE, Briancon N, Kokoeva MV, Maratos-Flier E, Flier JS. Remodeling of the arcuate nucleus energy-balance circuit is inhibited in obese mice. J Clin Invest (2012) 122(1):142-52. doi:10.1172/jci43134

69. Severi I, Perugini J, Mondini E, Smorlesi A, Frontini A, Cinti S, et al. Opposite effects of a high-fat diet and calorie restriction on ciliary neurotrophic factor signaling in the mouse hypothalamus. Front Neurosci (2013) 7:263. doi:10.3389/fnins.2013.00263

70. Hazlerigg DG, Wyse CA, Dardente H, Hanon EA, Lincoln GA. Photoperiodic variation in CD45-positive cells and cell proliferation in the mediobasal hypothalamus of the Soay sheep. Chronobiol Int (2013) 30(4):548-58. doi:10.3109/07420528.2012.754450

71. Migaud M, Butrille L, Batailler M. Seasonal regulation of structural plasticity and neurogenesis in the adult mammalian brain: focus on the sheep hypothalamus. Front Neuroendocrinol (2015) 37:146-57. doi:10.1016/ j.yfrne.2014.11.004

72. Huang L, DeVries GJ, Bittman EL. Photoperiod regulates neuronal bromodeoxyuridine labeling in the brain of a seasonally breeding mammal. J Neurobiol (1998) 36(3):410-20. doi:10.1002/(SICI)1097-4695(19980905) 36:3<410::AID-NEU8>3.0.CO;2-Z

73. Bernal J, Nunez J. Thyroid hormones and brain development. Eur J Endocrinol (1995) 133(4):390-8. doi:10.1530/eje.0.1330390

74. Lopez-Juarez A, Remaud S, Hassani Z, Jolivet P, Pierre Simons J, Sontag T, et al. Thyroid hormone signaling acts as a neurogenic switch by repressing Sox2 in the adult neural stem cell niche. Cell Stem Cell (2012) 10(5):531-43. doi:10.1016/j.stem.2012.04.008

75. Zoli M, Ferraguti F, Frasoldati A, Biagini G, Agnati LF. Age-related alterations in tanycytes of the mediobasal hypothalamus of the male rat. Neurobiol Aging (1995) 16(1):77-83. doi:10.1016/0197-4580(95)80010-O

Conflict of Interest Statement: The authors declare that the research was conducted in the absence of any commercial or financial relationships that could be construed as a potential conflict of interest.

Copyright (c) 2017 Lewis and Ebling. This is an open-access article distributed under the terms of the Creative Commons Attribution License (CC BY). The use, distribution or reproduction in other forums is permitted, provided the original author(s) or licensor are credited and that the original publication in this journal is cited, in accordance with accepted academic practice. No use, distribution or reproduction is permitted which does not comply with these terms. 